\title{
Energy and Exergy Analysis of a Finned-Plate Double Pass Solar Air Heater with Different Arrangement
}

\author{
Mohammed S. Fahmi' ${ }^{1}$, Wissam H. Khalil' ${ }^{1}$, Amer J. Shareef ${ }^{2}$ \\ ${ }^{1}$ Mechanical Engineering Department, Engineering College, University of Anbar, Ramadi, Iraq \\ ${ }^{2}$ Renewable Energy Research Center, University of Anbar, Ramadi, Iraq \\ Email: mechmsf85@gmail.com,wissam.gmw@uoanbar.edu.iq, eng.ajsh2006@uoanbar.edu.iq
}

How to cite this paper: Fahmi, M.S., Khalil, W.H. and Shareef, A.J. (2020) Energy and Exergy Analysis of a Finned-Plate Double Pass Solar Air Heater with Different Arrangement. Journal of Power and Energy Engineering, 8, 1-17.

https://doi.org/10.4236/jpee.2020.810001

Received: September 9, 2020

Accepted: October 16, 2020

Published: October 19, 2020

Copyright $\odot 2020$ by author(s) and Scientific Research Publishing Inc. This work is licensed under the Creative Commons Attribution International License (CC BY 4.0).

http://creativecommons.org/licenses/by/4.0/

\begin{abstract}
The present work investigated the solar collector system with triangular longitudinal fins fixed to the absorber surface at different configuration. Four models of collectors were manufactured with different absorber plates made from aluminum material. The experiments were carried out at the winter session in the climate of Iraq-Ramadi city with longitude (43.268) and latitude (33.43). The experiments have used three values from (0.027 to 0.037$) \mathrm{kg} / \mathrm{s}$. The results showed that the temperature difference increases gradually until midday and begins decreasing gradually until it becomes zero at sunset. Maximum temperatures difference has been obtained at the fourth type which is $\left(20.6^{\circ} \mathrm{C}\right)$, and maximum efficiency and exergetic efficiency $(99.9 \%)$, (43.08\%) respectively. A comparison has been made with previous works for thermal and exergetic efficiency. The comparison showed good compatibility between results; the percentage of error does not exceed 3\%. The results proved that the existence of fins was a good technique for enhancing the thermal performance of double pass solar collector with a non-effective increase in pressure drop.
\end{abstract}

\section{Keywords}

Solar Heater Collector, Exergy Efficiency, Double Pass Collector, Drying

Collector

\section{Introduction}

The interest in severe pollution in the environment as a result of the use of fossil fuels has created an urgent need to think of energy sources that have less environmental impact. One of the most important sources of energy that is consi- 
dered environmentally friendly is solar energy. Solar energy has been used for a long time to dry crops and was a source of light and heating. In the last century, interest in solar energy appeared after the energy crisis that occurred in 1973. After the increase in fossil fuel prices, researchers focused on developing solar powered systems. The most important of these systems were the solar heating complexes for water and air. Solar air collectors are very popular in heating homes and drying agricultural crops, as well as providing hot air for some industrial applications [1]. Among these collectors is the so-called single-pass solar air heater. These systems were of low efficiency and in order to increase their efficiency, a double-pass solar air heater was used. The thermal efficiency of these modified double pass has increased to increase the distance the air moves through which allows it to conduct heat exchange with the same absorber plate twice.

Despite the improvement in the efficiency of the solar air heater using the double pass, this efficiency is still below the level of ambition. In order to increase the thermal performance of these systems, the researchers thought of ways to improve the heat transfer by using augmentation techniques to generate turbulence inside the stream, which improves the heat exchange process between the air and the absorber plate [2].

The reliance on the first law of thermodynamics to measure the thermal performance of thermal systems has become deficient after the spread of the concept of exergy. Many researchers began studying the performance of solar air collectors, based on the concept of exergy that emerged from the application of the second law of thermodynamics [3].

Several studies [4] [5] [6] [7] [8] were conducted in order to increase the heat transfer of air passing through the solar collector by increasing the disturbance by the use of flaps, barriers, baffles, fins, and any other obstacles fixed to the absorber surface. These studies showed that a significant improvement occurs in thermal performance with a slight increase in pressure drop using these flow obstacles. Some researchers who thought about the recycling of waste materials introduce waste aluminum cans on the absorber plates as an augmentation technique for enhancement the heat transfer between the air and the absorber plates. These studies [9] [10] [11], show that in addition to reducing these waste cans from environment, they proved to be a good augmentation obstacle for their high thermal conductivity and their light weight and they enhance the heat transfer through the solar heater collectors.

The use of wire mesh is a good technique for the improvement of heat transfer through solar air heater. These techniques present their advantage by promoting a good mixing between air currents and save energy due to their high thermal conductivity and then release it at another time. Many researches [12]-[20] study these techniques and treat the wire mesh as a porous media. The use of these porous media enhances the thermal efficiency to a great extent. Heat stored in the porous media is lost more quickly due to the increase in heat transfer due to the porous media.

AfaqJasim, [21] conducted a comprehensive practical study to evaluate the 
improvement of the thermal performance of a double pass solar heater collector and compare its performance with that of a single pass. These collectors were used for the purposes of drying agricultural crops. Six solar collectors were studied using different types of fins. The study showed great agreement with previous studies and showed that the thermal gain of the double pass collector is much better than the one with the single pass. The study proved that the horizontal fins with the direction of flow are better in thermal performance than other shapes. Also the study shows that the fins of the helical shape are better than other types. Experimental experiments were conducted by Maytham Ali 2018 [22] to compare the performance of a single pass solar air collector with a double pass one using baffles. Several layers of wire mesh were used as an alternative to the absorber plate. The height between the two tracks of the double pass was changed from $3 \mathrm{~cm}$ to $7.5 \mathrm{~cm}$. In this study, the researcher dealt with the effect of changing the mass flow rate and changing the number of obstacles and its effect on thermal performance. The study showed that the best thermal performance was obtained by using seven baffles, a height of $3 \mathrm{~cm}$, and a temperature difference (between outlet and ambient) of 54 degrees Celsius. The study confirmed that increasing the number of obstacles leads to an increase in pressure drop.

Mustafa Adil et al. [23] examined the effect of changing the path of flow within the collector of solar air with multiple pass. Three models were tested theoretically and practically. The first model includes concurrent flow configuration, the second includes counter concurrent flow configuration while the last model was a so-called $\mathrm{U}$-shape flow configuration. The augmentation technique was using recycled aluminum cans (RAC's) fixed on the absorber plate. The results showed the using RAC's enhanced the thermal performance of all models. Also the results indicated that the U-shape is better than the other types in thermal performance.

To the best knowledge of the researches; the influence of extended surface on the single duct of double pass solar air collector (U-flow shape) has not been given enough attention in the past, which motivated the (current) study. The current study extracted many variables from previous research that lead to improving the performance of solar collectors. Thus, the current study is focused on the impact of increasing turbulence in the air flow on the thermal performance of a single duct double pass SAH collector using extended surfaces as air flow obstacles.

\section{Experimental Works}

Because of the development in the performance of solar collectors that work by using solar energy, many countries have begun to urge researchers to develop these systems to obtain the maximum benefit from them in providing heating without relying on traditional fuel. In this section, the practical aspect of solar air heater performance will be mentioned. The solar collector system with fins fixed to the absorber surface at different configuration will be studied. Practical expe- 
riments will be conducted in the city of Ramadi, Anbar Governorate-Iraq, which is located at longitude 43.268 east, latitude 33.43 north and height above sea level 59.8 asl. Experiments will take place in winter months: February 2020 and early March 2020. The period of the experiments extended from 09:00am to 17:00pm. The collectors face south with an angle of $\left(45^{\circ}\right)$.

\section{1) Construction of Experimental Set-Up}

Four models were manufactured for the double pass solar air collector (DPSAC) with equal dimensions and with different absorber plate, plywood with thickness $(2 \mathrm{~cm})$ used to manufacture the bases and sides for collector. Plywood was considered insulation to prevent heat leakage to surrounding, while the upper part of the collector was covered by transparent plastic (Perspex) to allowed solar radiation to pass through it and to prevent heat leakage out of the collector. The commercial Perspex panel is $4 \mathrm{~mm}$ thickness. The Dimensions of DPSAC were: length $(122 \mathrm{~cm})$, width $(60 \mathrm{~cm})$ and height $(25 \mathrm{~cm})$. The shape of the solar collector is rectangular of $(100 \mathrm{~cm})$ length and $(60 \mathrm{~cm})$ width and the end of the collector is trapezoidal shape of length of $(22 \mathrm{~cm})$ with upper base and lower base of $(60 \mathrm{~cm}, 14 \mathrm{~cm})$ respectively. All parts of collector painted black color to increase absorbitivity and reduce heat loss. The collector divided into channel upper and lower by absorber plate. Air was provided to the system with the help of a blower fan. In order to obtain the largest amount of incident solar radiation with all of the time of experiments, the tilt angle of the SAH is selected to be $\left(45^{\circ}\right)$.

All absorber plats used in this experiment was made from aluminum with a thickness of $(1 \mathrm{~mm})$. The dimensions of the absorber plate were $(85 \mathrm{~cm} \times 56 \mathrm{~cm})$ and painted with black color to keep high absorbance. The Aluminum plate is used for construction of absorber plate, it has a thermal conductivity of $(K=217$ $\mathrm{w} / \mathrm{m} \cdot \mathrm{k})$ at $\left(\right.$ Temperature $\left.=100^{\circ} \mathrm{C}\right)$, absorptivity of $(0.94)$ with transmissivity (0.09) [24]. Absorber plate was placed at $(12.5 \mathrm{~cm})$ from collector base and lead to division inside collector to upper and lower channel and made empty region with length $(15 \mathrm{~cm})$ to forced air to change its direction from upper channel to lower channel and exit from the collector. It is thus considered a double pass solar air collector. Four models were designed and manufactured depending on the shape of absorber plate. The first model is a flat plate without longitudinal fins and this model will be taken as a reference one. The second model is a flat plate containing six longitudinal fins with length $(55 \mathrm{~cm})$. The fins are of triangular shape with hydraulic diameter of $(5 \mathrm{~cm})$. In third model, the longitudinal triangular fins are placed symmetrically on a flat absorption plate at an angle of inclination $\left(45^{\circ}\right)$ with different lengths but the sum of fins length is equal length fins in second model and same hydraulic diameter. The last model has six of the longitudinal triangular fins were placed upper the absorber plate and six under the absorber plate perpendicular with airflow. The models are shown in Figure 1. The whole structure of the experimental setup is shown in Figure 2. Table 1 present the classification of each model used in experiments.

2) Maintaining the Integrity of the Specifications 


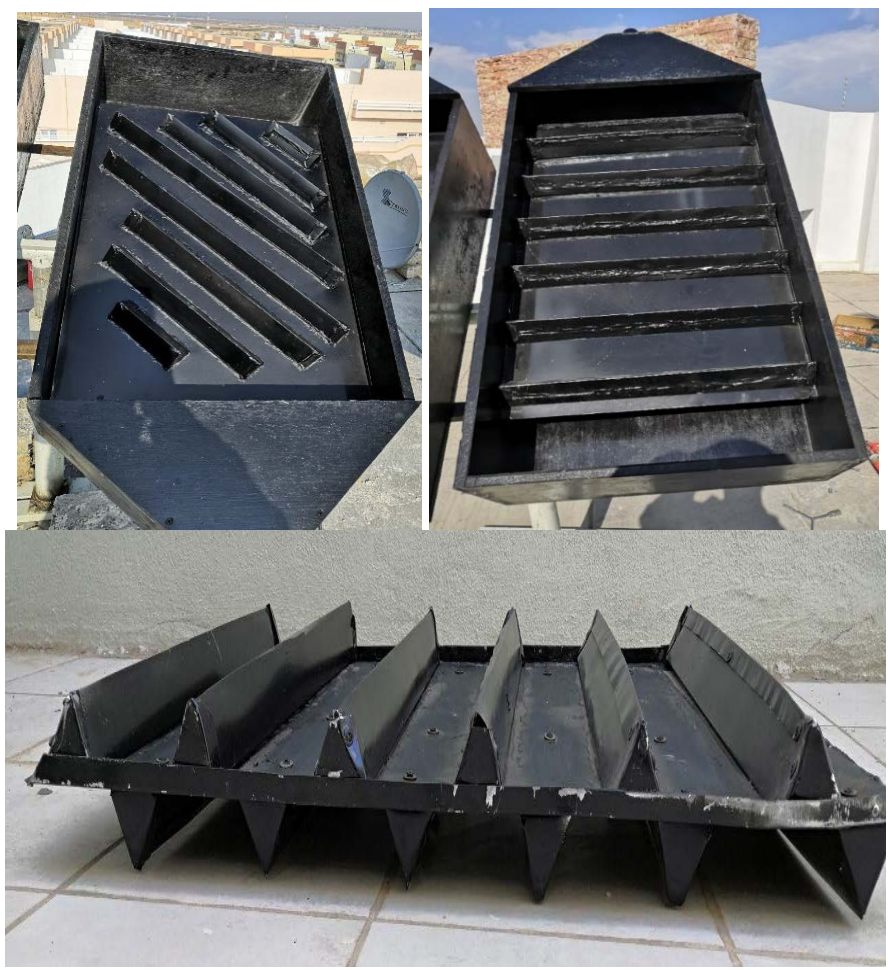

Figure 1. The mode used in experiments.

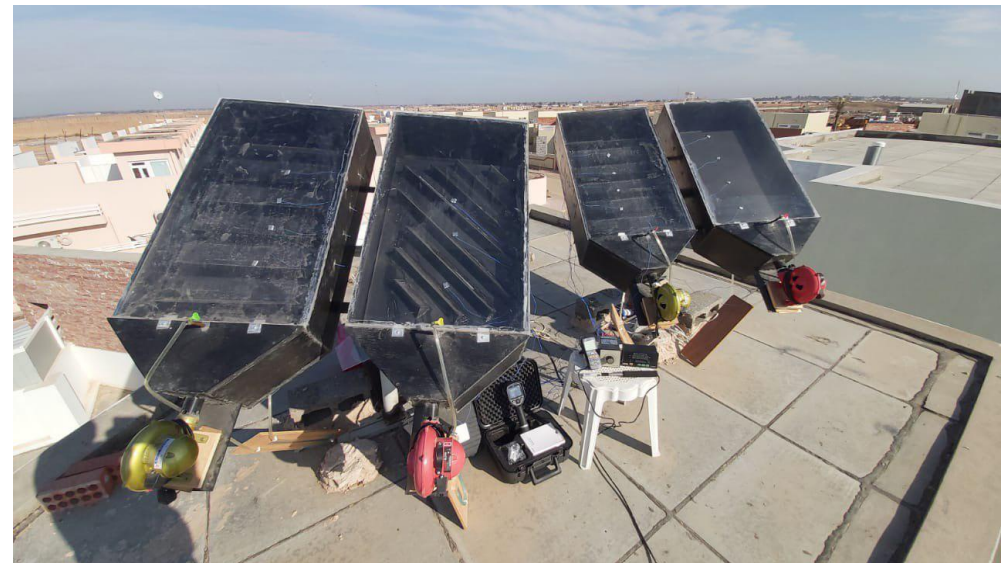

Figure 2. The experimental set-up.

Table 1. Classification of models for the solar collectors used in the current work.

\begin{tabular}{ccc}
\hline 1 & Type A & Flat Plate \\
2 & Type E & With fins placed perpendicular on airflow \\
3 & Type F & With fins placed inclined at an angle $45^{\circ}$ \\
4 & Type G & With double fins placed perpendicular on airflow \\
\hline
\end{tabular}

\section{Thermal Performance Analysis}

\subsection{Energy Analysis}

The useful heat gain $\left(Q_{u}\right)$ is given by [25] [26]: 


$$
\begin{gathered}
Q_{u}=m^{\circ} C_{p} \Delta T \\
\Delta T=\left(T_{\text {out }}-T_{\text {in }}\right)
\end{gathered}
$$

where:

$$
\begin{aligned}
& C_{p}=\text { specific heat }\left(\mathrm{J} / \mathrm{kg} \cdot{ }^{\circ} \mathrm{C}\right)[27] \\
& \qquad C_{p}=1.0057+0.000066\left(T_{\text {ave }}-27\right)
\end{aligned}
$$

The air mass flow rate $\left(m^{\circ}\right)$ is given by:

$$
m^{\circ}=\rho A_{c} V
$$

where: $A_{c}=$ the across section area of the collector inlet duct $\left(\mathrm{m}^{2}\right)$.

The thermal efficiency of the heater $\left(\eta_{t h}\right)$ is defined as the useful heat gain rate of the air across the heater to the solar energy incident on the heater surface which is given by [27]:

$$
\eta_{t h}=\frac{Q_{u}}{I A_{b}}
$$

where: $A_{b}=$ the area of absorber plate $\left(\mathrm{m}^{2}\right)$.

$I=$ the total solar radiation incident on the heater $\left(\mathrm{W} / \mathrm{m}^{2}\right)$.

\subsection{Exergy Analysis}

Exergy (sometimes called availability) is a measure of the maximum useful work that can be done by the system interacting with a constant conditions environment.

Exergy can be obtained from the following analyzing [26] [28] [29]

The exergy efficiency

$$
\begin{gathered}
\left(\eta_{E X}\right)=\frac{E X_{\text {out }}}{E X_{\text {in }}} \\
E X_{\text {out }}=m^{\circ}\left[h_{\text {out }}-h_{\text {in }}-T_{e}\left(S_{\text {out }}-S_{\text {in }}\right)\right] \\
E X_{\text {in }}=\left(1-\frac{T_{e}}{T_{s}}\right) Q_{s} \\
\Delta S=S_{\text {out }}-S_{\text {in }}=C_{p} \ln \frac{T_{\text {out }}}{T_{\text {in }}}-R \ln \frac{P_{\text {out }}}{P_{\text {in }}} \\
Q_{s}=I(\tau \alpha) A_{c}
\end{gathered}
$$

where:

$$
\begin{aligned}
& E X_{\text {out }}=\text { Exergy outlet }(\mathrm{kJ}) ; \\
& E X_{\text {in }}=\text { Exergy inlet }(\mathrm{kJ}) ; \\
& Q_{s}=\text { the solar energy absorbed by the collector absorber surface. }
\end{aligned}
$$

\section{Results and Discussion}

The results of the current study were compared with that published in literature surrey. Figure 3 shows the thermal efficiency comparison between the present DPSAC without thermal storage system using type $F$ and $G$ with previous work 


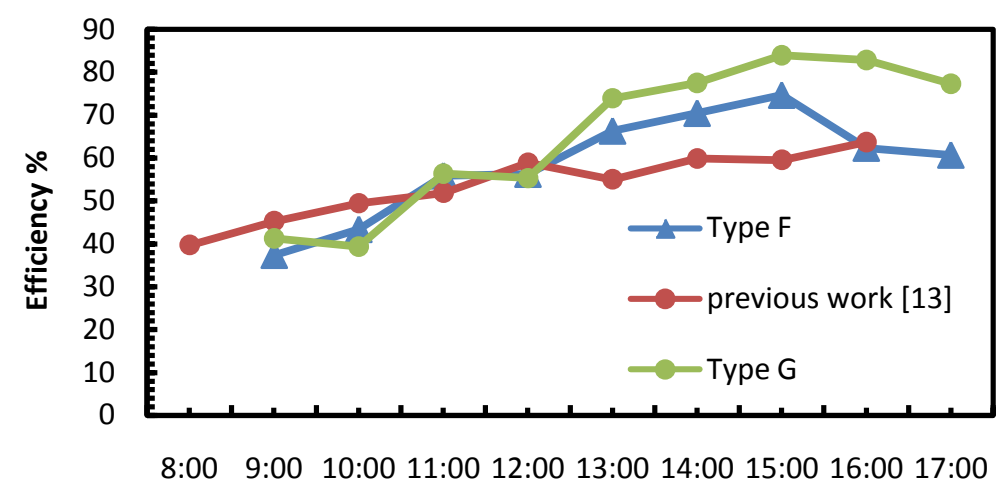

Time of the day (hr)

(a)

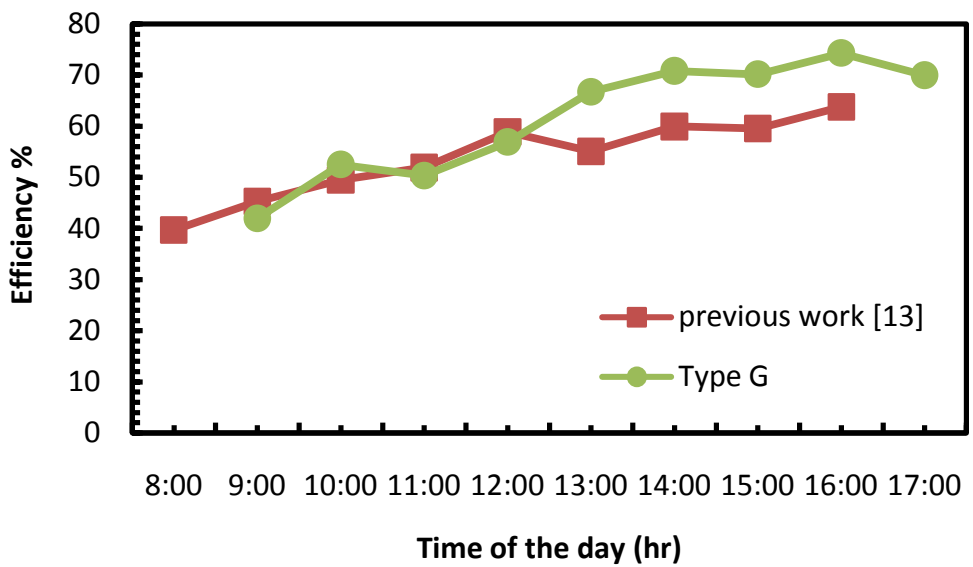

(b)

Figure 3. Comparison thermal efficiency with previous works, (a) Type G, and F [13] at $3 / 2 / 2020$, (b) Type G [13] at 8/3/2020.

of Nowzari, et al., 2011 [13]. From these figures, it can be shown that the convergence is very good with the previous work until noon and reach to an approximately $99 \%$ convergence. After that, the thermal efficiency of DPSAC, type $\mathrm{F}$, and $\mathrm{G}$ in the present work is better than from previous work that using wire mesh as heat transfer enhancement technique to improve heat transfer between the absorber plate and air.

It's obvious from Figure 4 that the solar radiation intensity increase linearly from the starting reading to until it reach to peak values at noon or beyond little, then it start to decrease until it faded at sunset. It was noted that the peak solar radiation was $1013.12 \mathrm{~W} / \mathrm{m}^{2}$ in $27 / 2 / 2020$. The behavior of solar radiation during experiment times will strongly affect the thermal performance of the solar heater collector.

Figure 5 depicted the hourly temperature distribution for DPSAC for types A, E, F, and G respectively on a clear day on 17 February 2020. The temperatures were observed normal behaver of the inlet, outlet, and ambient. Which was recorded maximum temperature at midday and begun to decrease gradually. It's clear from this figure that there is a gradual increase in temperature from 09:00 a.m. 


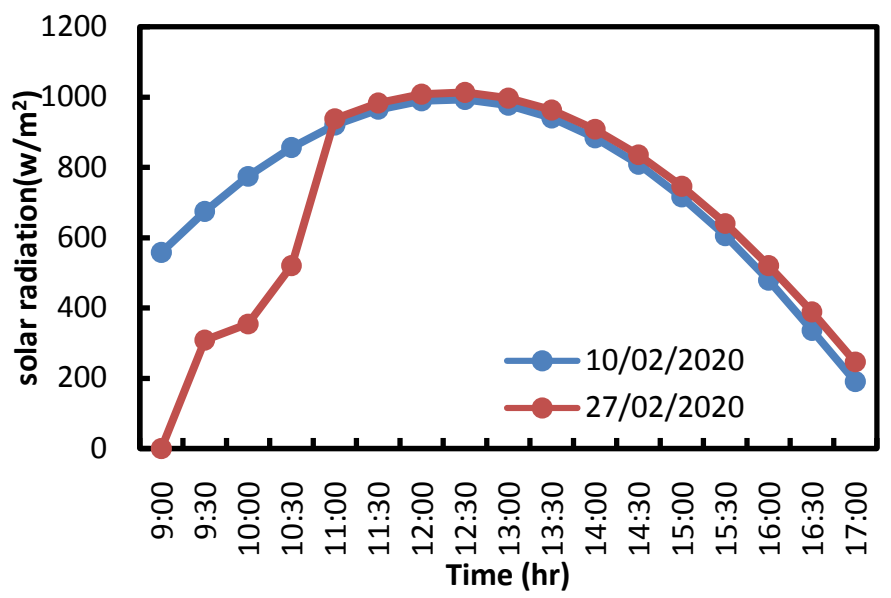

Figure 4. Hourly solar radiation, at 10/2/2020, 27/2/2020.

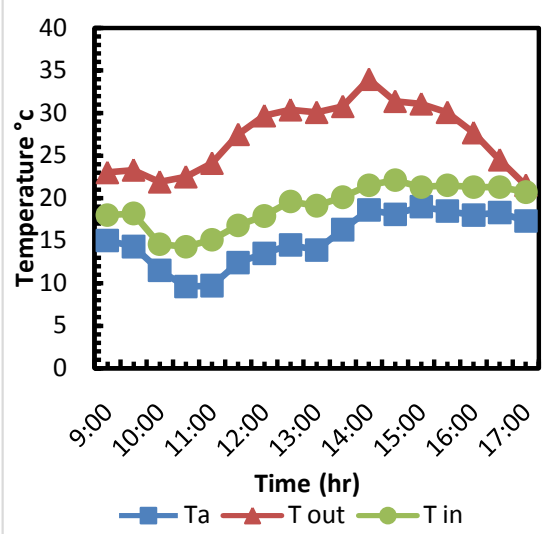

(a)

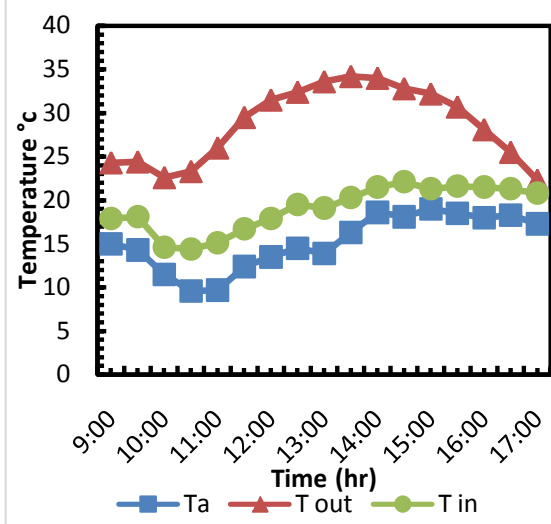

(c)

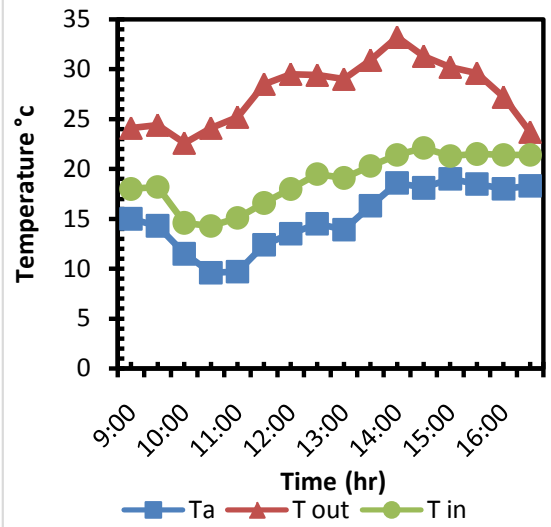

(b)

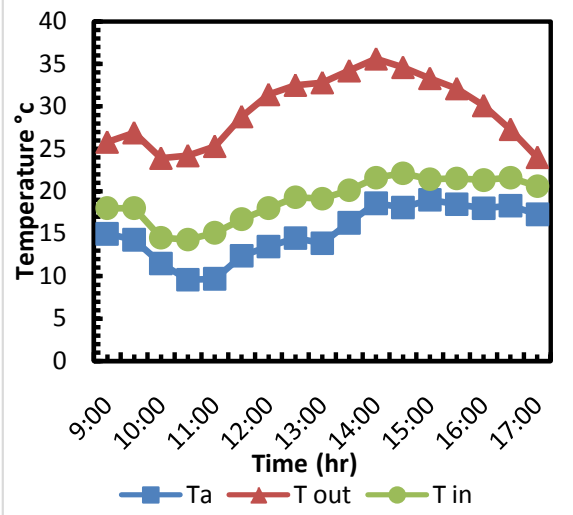

(d)

Figure 5. Hourly temperature variation of the ambient, inlet, and outlet for different types of collector versus time at 17/2/202020, (a) Type A, (b) Type E (c) Type F, (d) Type G.

to higher values at 01:30 p.m. After this higher value, it can be noticed a decrease in the temperature values until the outside temperature values (from the collector) close to that of incoming air at the end of the day. This behavior is normal due to the decrease in the value of incident energy due to the decrease in solar 
radiation after midday. The maximum outlet temperature from the collector has been obtained in this present work, which is $\left(51.5^{\circ} \mathrm{C}\right)$ in type $(\mathrm{G})$ at $21 / 2 / 2020$, shows in Figure 6.

Figure 7 depicted the hourly temperature distribution for DPSAC for types A,

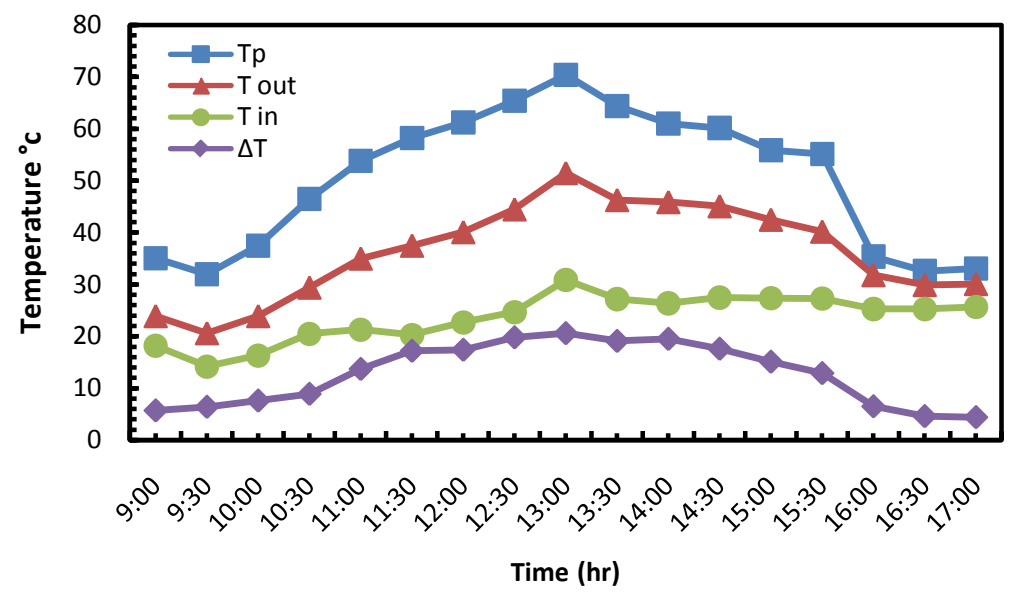

Figure 6. Maximum outlet temperature from type $(\mathrm{G})$.

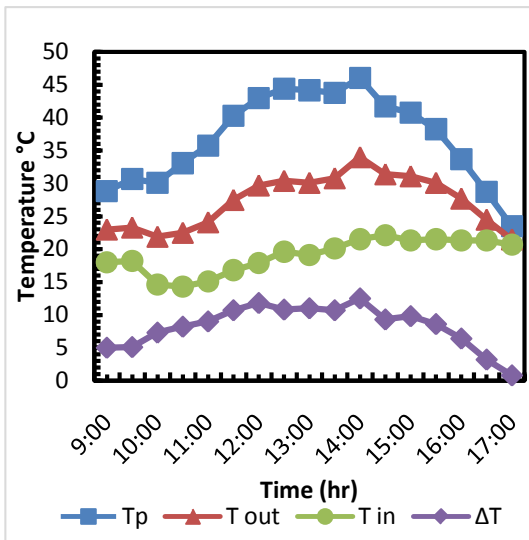

(a)

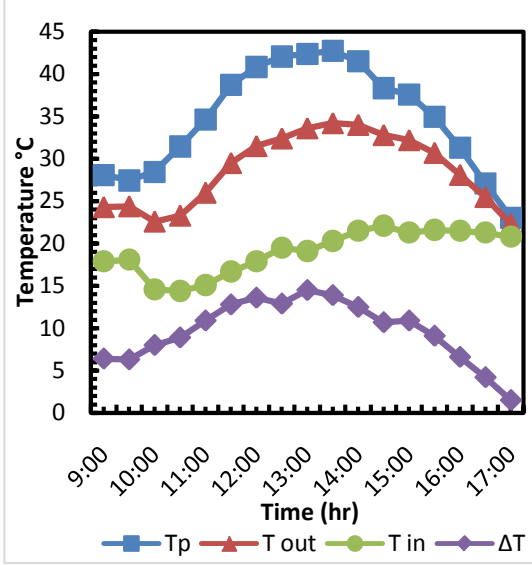

(c)

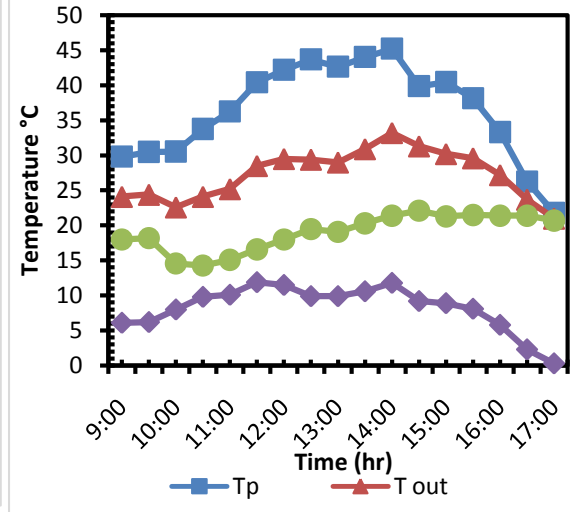

(b)

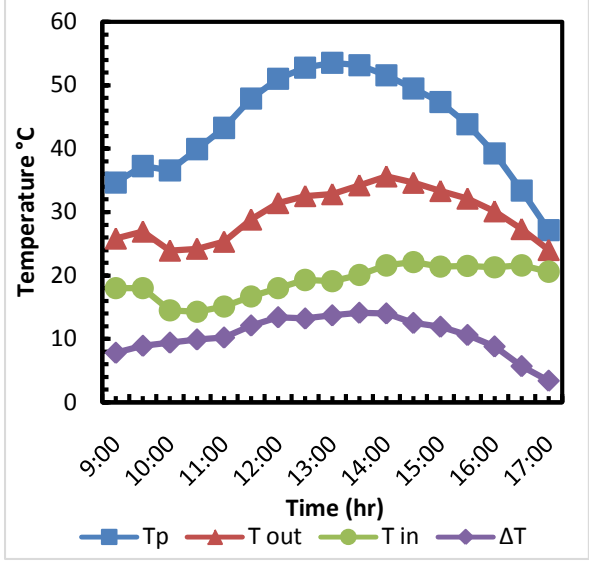

(d)

Figure 7. Hourly temperatures variation versus time at 17/2/202020. (a) Type A, (b) Type E, (c) Type F, (d) Type G. 
E, F, and G respectively on a clear day on 17 February 2020. From the figures, it was noted that the temperature difference of air takes the same behavior of the absorber plate temperature, increases with time and reaches its maximum value at 01:00 p.m., and begins to decrease gradually. The highest value of the temperature difference was obtained in the present work, at 01:00 p.m. to be $20.6^{\circ} \mathrm{C}$ in $21 / 2 / 2020$ at type $G$, because this type contains double fins that led to increase heat transfer area more than from other types.

The effect of solar radiation on the thermal efficiency was depicted in Figure 8 for DPSAC for types A, E, F, and G respectively on a clear day on 17 February 2020. For each half hours through the daytime with solar radiation, from these figures, it was noted the thermal efficiency was proportionate with solar radiation received, so that, the thermal efficiency of DPSAC increases distinctly when solar radiation increased. This is due to the releasing of heat storage in wax a sit begun to solidify. Maximum thermal efficiency was obtained in DPSAC for type $\mathrm{G}$ in $23 / 2 / 2020$, which is $99.9 \%$. Because of this type contains extended surfaces that led to increase heat transfer area more than from other types, increase the temperature difference between inlet and outlet and obtained an increase in heat gain, which led to increase in thermal efficiency, shows in Figure 9. Figure 10 shown the thermal efficiency for DPSAC for types A, E, F, and G respectively on

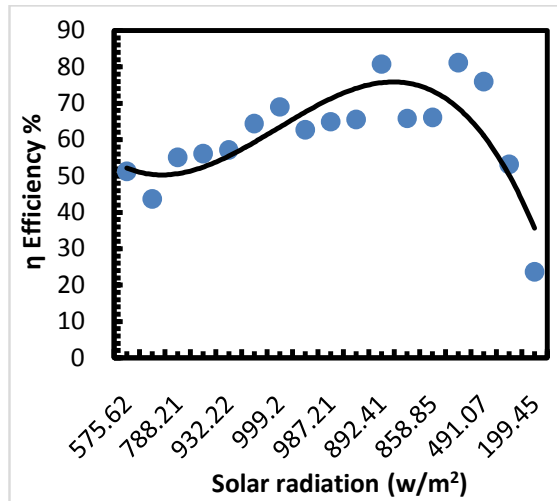

(a)

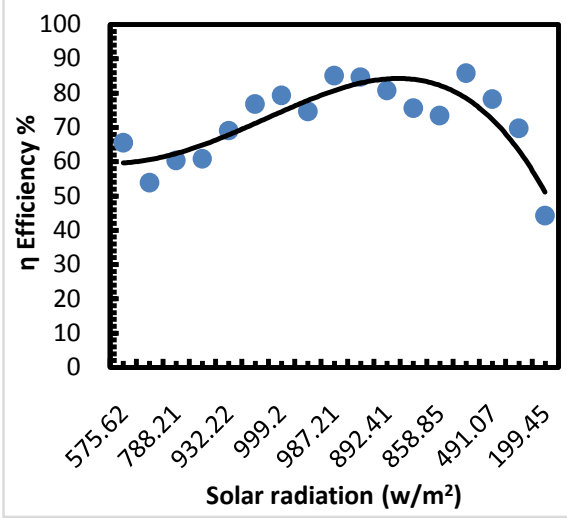

(c)

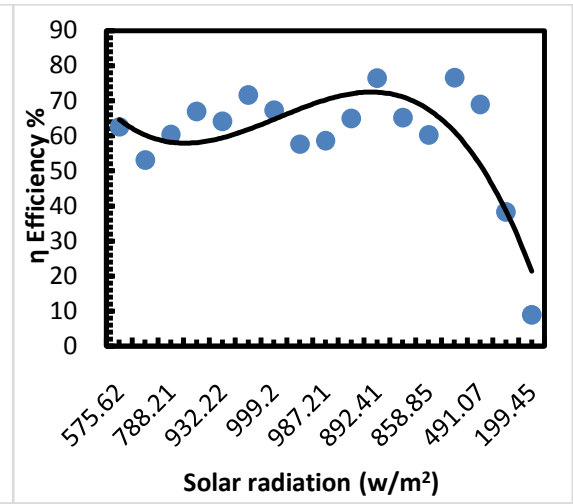

(b)

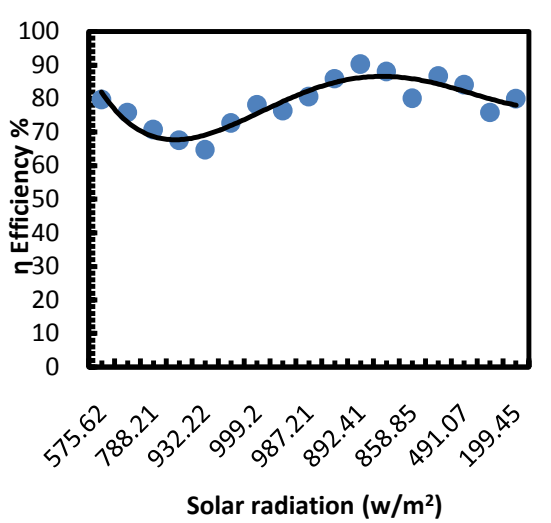

(d)

Figure 8. Thermal efficiency with solar radiation at 17/2/202020. (a) Type A, (b) Type E, (c) Type F, (d) Type G. 


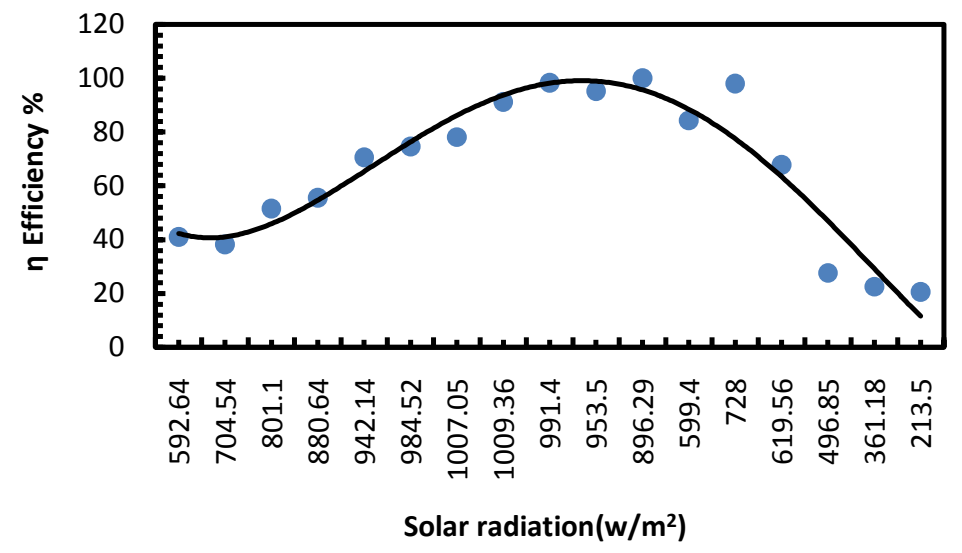

Figure 9. Maximum thermal efficiency from type $(G)$.

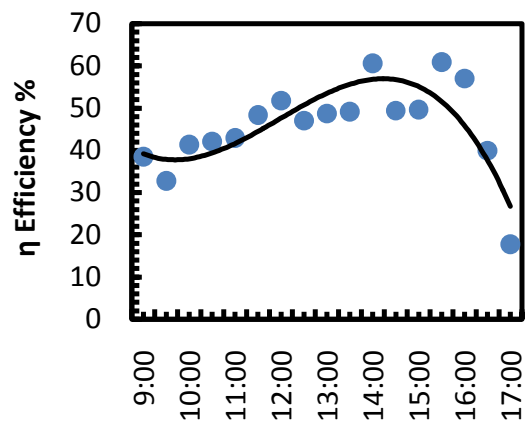

Time (hr)

(a)

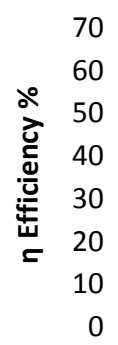

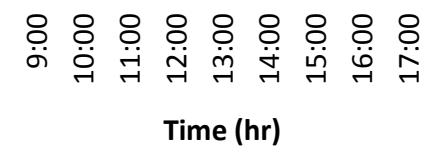

(c)

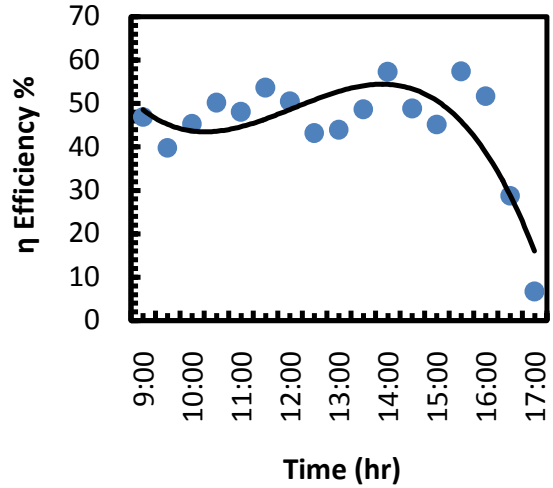

(b)

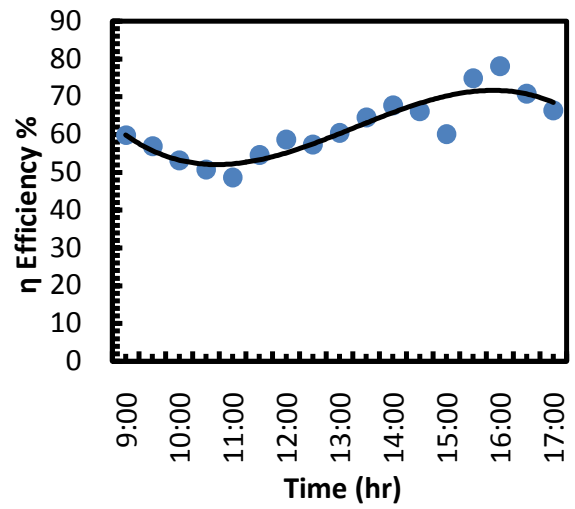

(d)

Figure 10. Thermal efficiency versus time at 17/2/202020. (a) Type A, (b) Type E, (c) Type F, (d) Type G.

a clear day on 17 February 2020 from 09:00 a.m. to 05:00 p.m. From these figures, it was noted the thermal efficiency was increased until midday and begin decreased gradually. In Figure 11 it was noted the DPSAC type G gives the highest thermal efficiency from other types. This is due to the increasing of absorber plate area rather than other types. Type $\mathrm{E}$ and $\mathrm{F}$ give thermal efficiency highest from type A (flat plate). Figure 12 shows that the exergetic efficiency for DPSAC for model $G$ on a clear day on 2nd of March 2020. From this figures, 


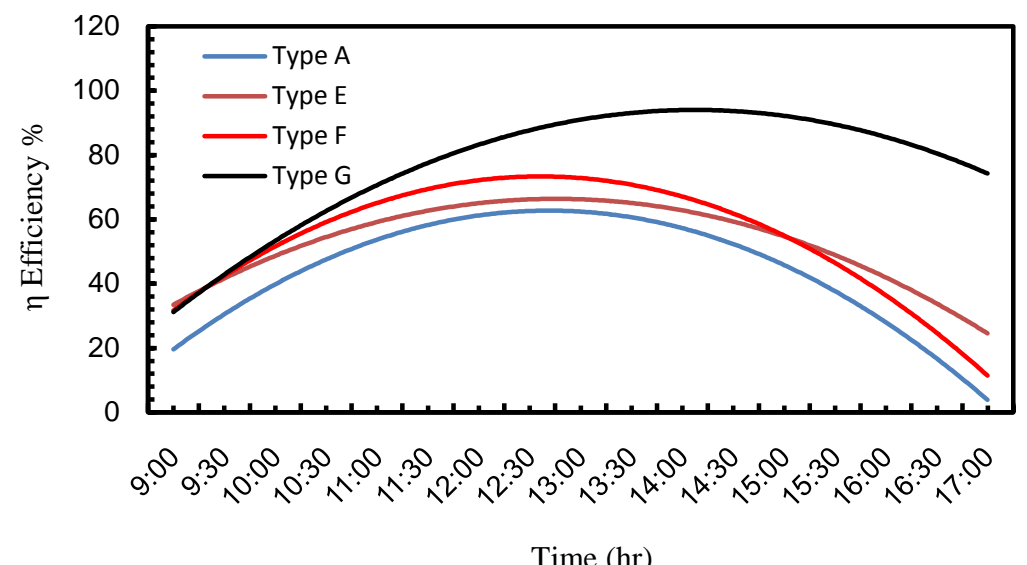

(a)

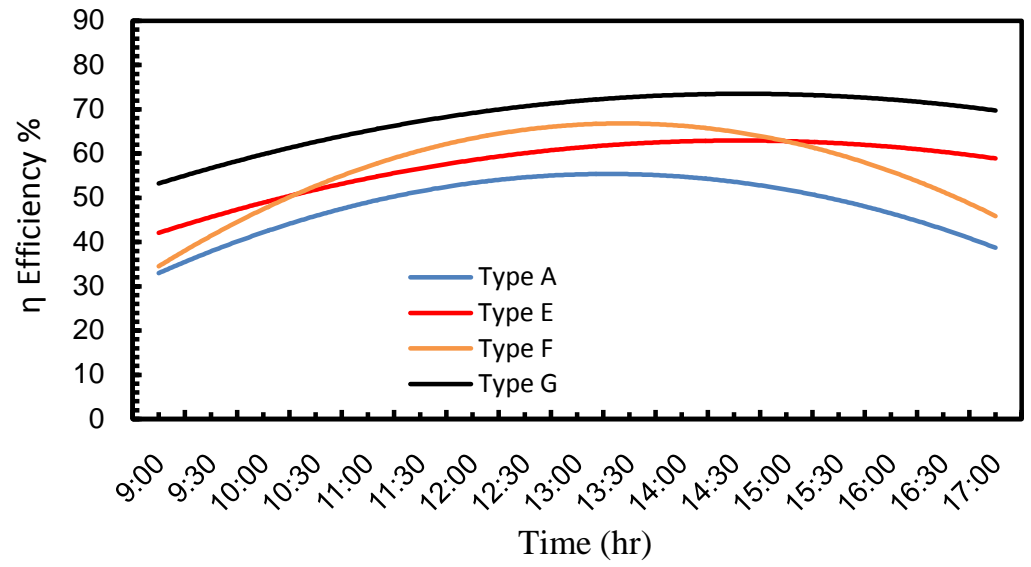

(b)

Figure 11. Comparison thermal efficiency between different types of DPSAC, (a) at $21 / 2 / 2020$, (b) at $7 / 3 / 2020$.

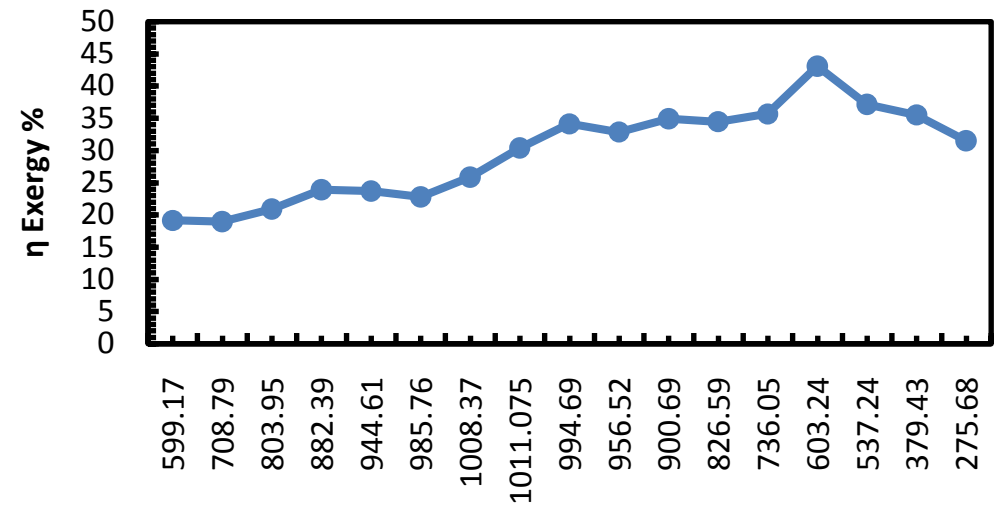

\section{solar radiation $\left(\mathrm{w} / \mathrm{m}^{2}\right)$}

Figure 12. Maximum exergetic efficiency for type $(G)$.

maximum exergy efficiency was obtained in DPSAC for type G in $2 / 3 / 2020$, which is $43.08 \%$.

Figure 13, shows comparison exergy efficiency between types A, E, F, and G, on $21 / 2 / 2020$ and $7 / 3 / 2020$. From this figure, it was noted the DPSAC type $G$ 


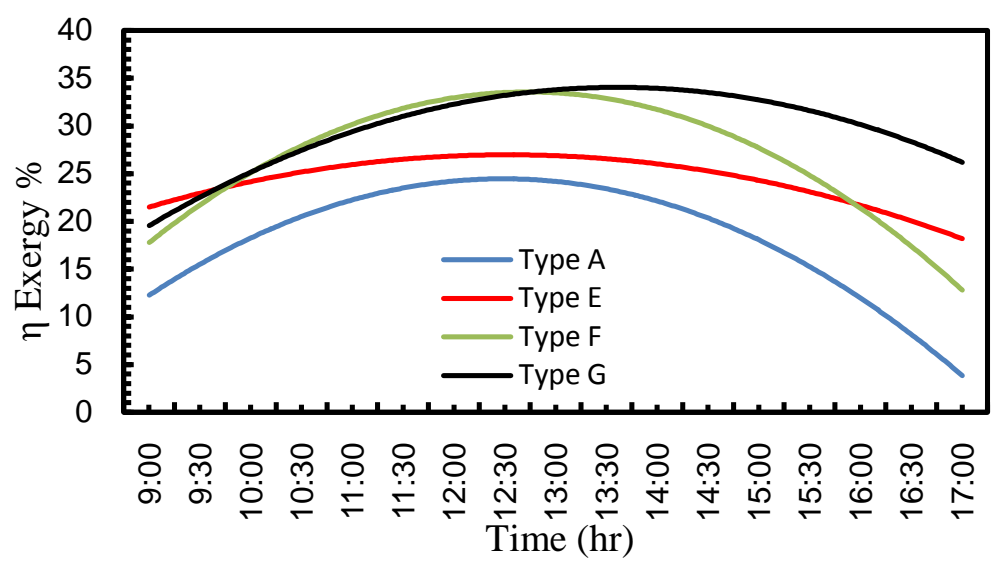

(a)

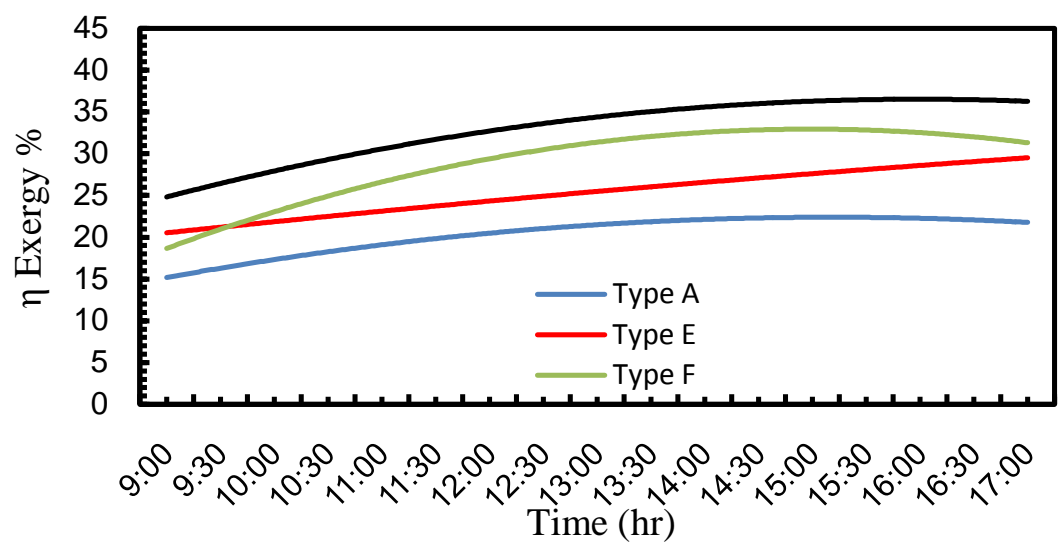

(b)

Figure 13. Comparison exergetic efficiency between different types of DPSAC, (a) at $21 / 2 / 2020$, (b) at $7 / 3 / 2020$.

gives the highest exergy efficiency from other types. Type E and F give exergy efficiency highest from type A (flat plate).

The effect of mass flow rate on the thermal efficiency with time for different types of DPSAC, at mass flow rate $(0.027 \mathrm{~kg} / \mathrm{s}-0.034 \mathrm{~kg} / \mathrm{s}-0.037 \mathrm{~kg} / \mathrm{s})$ is shown in Figure 14. From these figures, it was noted thermal efficiency increased with increasing of mass flow rate because the thermal efficiency is proportional to the mass flow rate.

Figure 15 shows the effect of mass flow rate on the exergetic efficiency with time for different types of DPSAC, at mass flow rate $(0.027 \mathrm{~kg} / \mathrm{s}-0.034 \mathrm{~kg} / \mathrm{s}$ $0.037 \mathrm{~kg} / \mathrm{s})$. From these figures, it was noted exergetic efficiency increased with the mass flow rate increased because the exergetic efficiency is proportional to the mass flow rate.

\section{Conclusion}

An experimental apparatus was designed and fabricated to study the effect of existing extended surfaces of different configurations on the performance of DPSAC. The main conclusions drawn from the results show that an increase in area of 


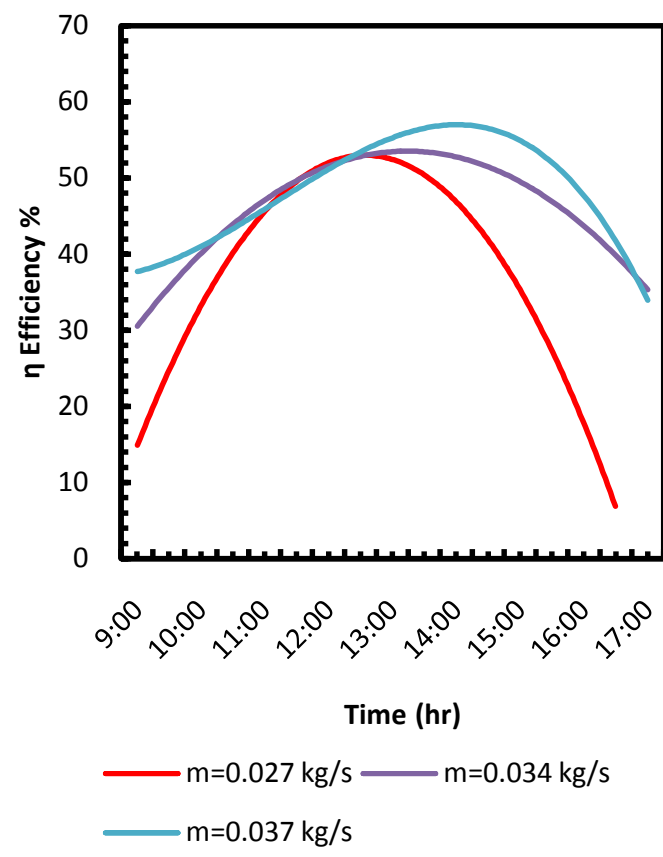

(a)

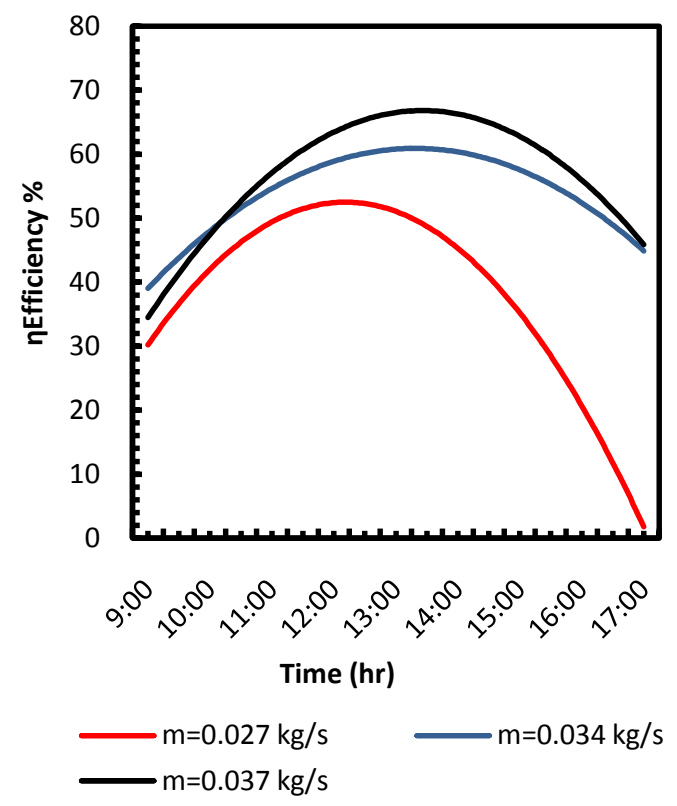

(c)

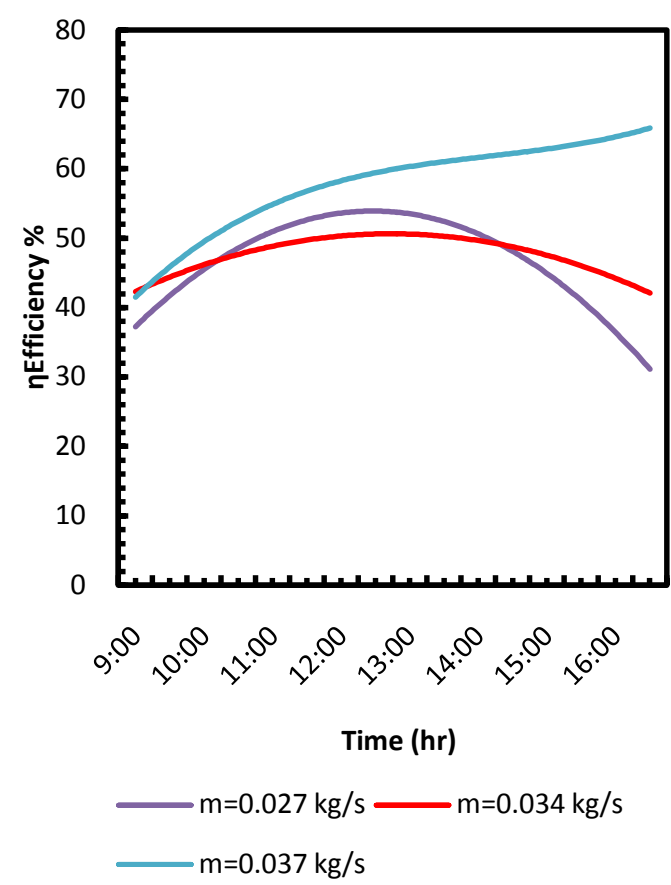

(b)

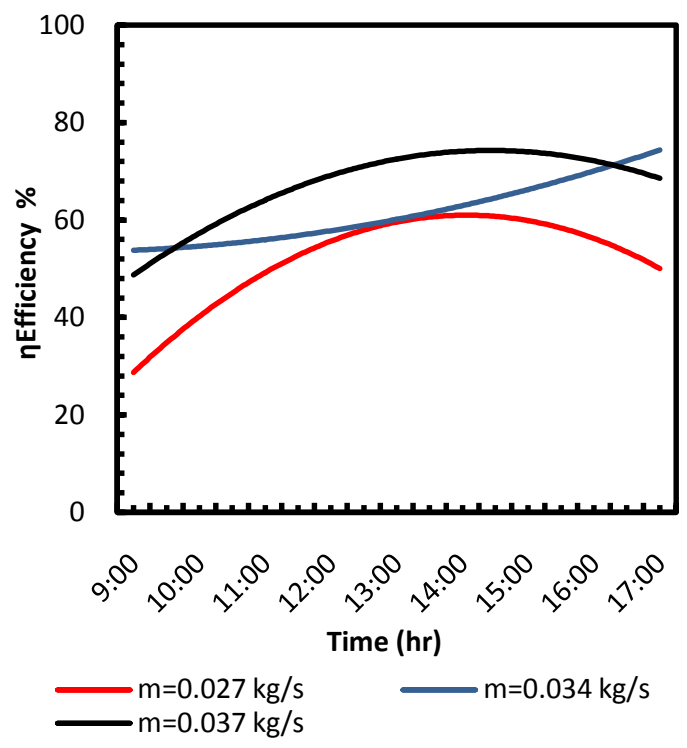

(d)

Figure 14. Effect of mass flow rate on thermal effeciency, (a) Type A, (b) Type E, (c) Type F, (d) Type G.

the absorber plate led to an increase in heat transfer by adding fins to the absorber plate. These extended surfaces (triangular fins) led to a higher intensity of turbulence, which led to a good mixing of the cold and hot air. The collector that has fins both on upper and lower surfaces of the collector present higher thermal efficiency. As the second law of thermodynamic is a good tool for the study of such collectors, this study presents the exergetic efficiency of such collators. The higher exergetic efficiency obtained collector type G, which is (43.08\%). Also the 


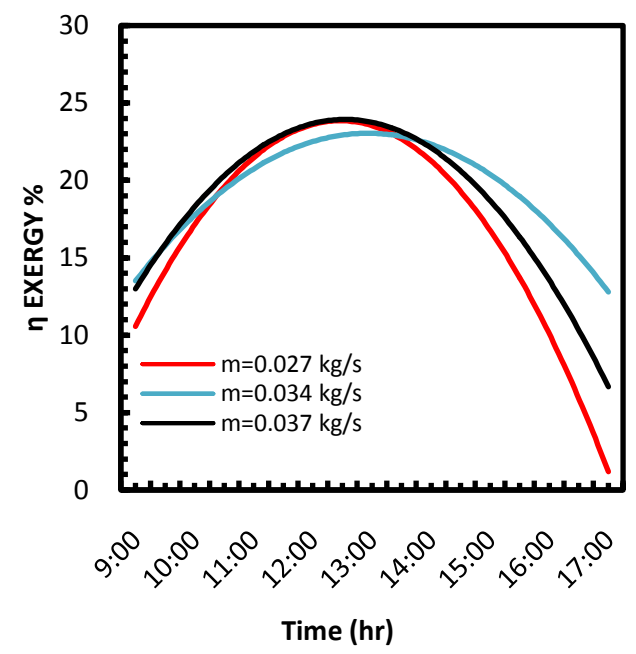

(a)

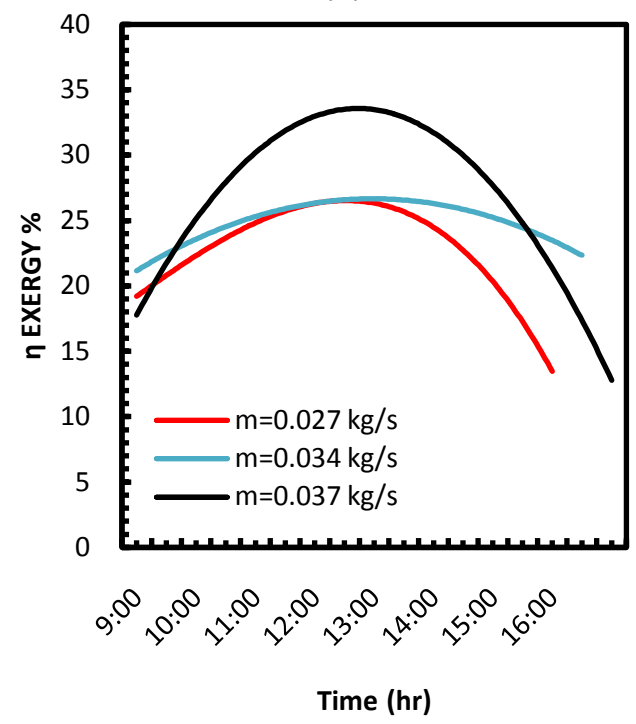

(c)

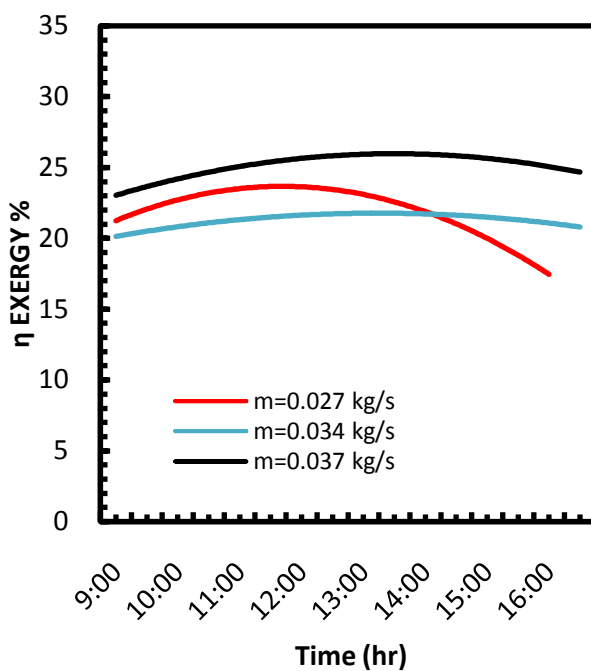

(b)

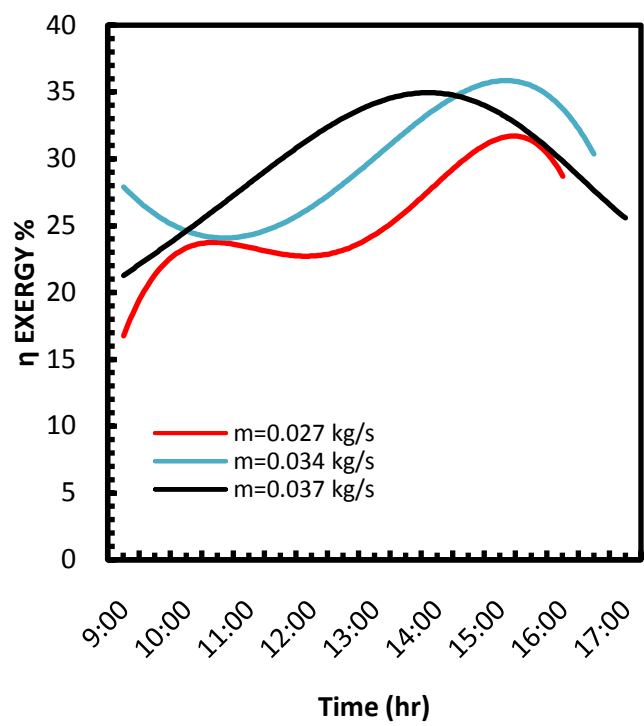

(d)

Figure 15. Effect of mass flow rate on exergetic efficiency, (a) Type A, (b) Type E, (c) Type F, (d) Type G.

maximum temperature difference was being obtained is $\left(20.6^{\circ} \mathrm{C}\right)$ at collector type $\mathrm{G}$. The study concludes that there is a possibility of applying these collectors to provide a suitable temperature difference for heating purposes. Extensive studies must be conducted to show the effect of using expanded surfaces on pressure drops and the associated increase in pumping power.

\section{Conflicts of Interest}

The authors declare no conflicts of interest regarding the publication of this paper.

\section{References}

[1] Heiskanen, E., Lovio, R. and Jalas, M. (2011) Path Creation for Sustainable Con- 
sumption: Promoting Alternative Heating Systems in Finland. Journal of Cleaner Production, 19, 1892-1900. https://doi.org/10.1016/j.jclepro.2011.02.005

[2] Abdullah, A.S., Al-sood, M.M.A., Omara, Z.M., Bek, M.A. and Kabeel, A.E. (2018) Performance Evaluation of a New Counter Flow Double Pass Solar Air Heater with Turbulators. Solar Energy, 173, 398-406. https://doi.org/10.1016/j.solener.2018.07.073

[3] Dincer, I. and Ratlawwala, T.A.H. (2013) Important of Exergy for Analysis, Improvement Design, and Assessment. Energy and Environment Journal, 2, 335-349. https://doi.org/10.1002/wene.63

[4] Fudholi, A., Ruslan, M.H., Othman, M.Y., Yahya, M., Zaharim, A. and Sopian, K. (2010) Experimental Study of the Double-Pass Solar Air Collector with Staggered Fins. Proceedings of the 9th WSEAS International Conference on System Science and Simulation in Engineering, October 2010, 410-414.

[5] Fudholi, A., Sopian, K., Ruslan, M.H., Othman, M.Y. and Yahya, M. (2011) Thermal Efficiency of Double Pass Solar Collector with Longitudinal Fins Absorbers. American Journal of Applied Sciences, 8, 254-260. https://doi.org/10.3844/ajassp.2011.254.260

[6] Ramadan, M.R.I., Shalaby, S.M. and Moharram, B.M. (2011) Investigation of Thermal Performance of Double-Pass Flat Plat and v-Corrugated Plate Solar Air Heaters. Energy, 36, 1076-1086. https://doi.org/10.1016/j.energy.2010.11.042

[7] Sharma, S.P. and Saha, S.N. (2017) Thermohydraulic Performance of Double Flow Solar Air Heater with Corrugated Absorber. International Journal of Energy and Power Engineering, 11, 779-785.

[8] Kalash, A.R., Shijer, S.S. and Habeeb, L.J. (2020) Thermal Performance Improvement of Double Pass Solar Air Heater. Journal of Mechanical Engineering Research and Developments, 43, 355-372.

[9] Ozgen, F., Esen, M. and Esen, H. (2009) Experimental Investigation of Thermal Performance of a Double-Flow Solar Air Heater Having Aluminium Cans. Renewable Energy, 34, 2391-2398. https://doi.org/10.1016/j.renene.2009.03.029

[10] González, S.M., Larsen, S.F., Hernández, A. and Lesino, G. (2014) Thermal Evaluation and Modeling of a Double-Pass Solar Collector for Air Heating. Energy Procedia, 57, 2275-2284. https://doi.org/10.1016/j.egypro.2014.10.235

[11] Adil, M., Ibrahim, O., Hussein, Z. and Waleed, K. (2015) Experimental Investigation of SAHs Solar Dryers with Zigzag Aluminum Cans. International Journal of Energy and Power Engineering, 4, 240-247. https://doi.org/10.11648/j.ijepe.20150405.11

[12] Korti, A.I.N. (2015) Numerical 3-D Heat Flow Simulations on Double-Pass Solar Collector with and without Porous Media. Journal of Thermal Engineering, 1, 10-23. https://doi.org/10.18186/jte.86295

[13] Nowzari, R., Aldabbagh, L.B.Y. and Mirzaei, N. (2011) Experimental Study on Double Pass Solar Air Heater with Mesh Layers as Absorber Plate. International Journal of Electronics, Mechanical and Mechatronics Engineering, 3, 673-682.

[14] Ho, C., Lin, C., Yang, T. and Chao, C. (2014) Recycle Effect on Device Performance of Wire Mesh Packed Double-Pass Solar Air Heaters. Energies, 7, 7568-7585. https://doi.org/10.3390/en7117568

[15] Aldabbagh, L.B.Y., Egelioglu, F. and Ilkan, M. (2010) Single and Double Pass Solar Air Heaters with Wire Mesh as Packing Bed. Solar Energy, 35, 3783-3787. https://doi.org/10.1016/j.energy.2010.05.028

[16] Ramani, B.M., Gupta, A. and Kumar, R. (2010) Performance of a Double Pass Solar 
Air Collector. Solar Energy, 84, 1929-1937.

https://doi.org/10.1016/j.solener.2010.07.007

[17] Omojaro, A.P. and Aldabbagh, L.B.Y. (2010) Experimental Performance of Single and Double Pass Solar Air Heater with Fins and Steel Wire Mesh Absorber. Applied Energy, 87, 3759-3765. https://doi.org/10.1016/j.apenergy.2010.06.020

[18] Maraba, G. (2012) An Experimental Study on Enhancement of Heat Transfer in a Solar Air Heater Collector by Using Porous Medium. October 2012 Izmir, Department of Mechanical Engineering, Iztech. A Thesis Submitted to the Graduate School of Engineering and Sciences of İzmir Institute of Technology.

[19] Velmurugan, P and Kalaivanan, R. (2016) Energy and Exergy Analysis in Double-Pass Solar Air Heater. Sadhana, 41, 369-376. https://doi.org/10.1007/s12046-015-0456-5

[20] Amin Mezoued, M. and Kaabi, A. (2013) Effect of Using Packing Material on the Performances of the Double Pass Photovoltaic-Thermal (PVT) Air Heater. International Journal of Thermal \& Environmental Engineering, 5, 61-70.

[21] Mahmood, A.J. (2015) Experimental Study of a Solar Air Heater with New Arrangement of Transverse Longitudinal Baffles and Wire Mesh Layers. PhD Thesis, Eastern Mediterranean University, Gazimağusa.

[22] Al-Neama, M.A.J. (2018) Performance Enhancement of Solar Air Collectors Applied for Drying Processes. Ph.D. Thesis, Szent István University, Gödöllö.

[23] Al-Damook, M., Obaid, Z.A.H., Al Qubeissi, M., Dixon-Hardy, D., Cottom, J. and Heggs, P.J. (2019) CFD Modeling and Performance Evaluation of Multipass Solar Air Heaters. Numerical Heat Transfer, Part A: Applications, 76, 438-464. https://doi.org/10.1080/10407782.2019.1637228

[24] Holman, J.P. (2010) Heat Transfer. 10th Edition, McGraw-Hill, New York.

[25] Duffie, J.A. and Beckman, W.A. (1991) Solar Engineering of Thermal Processes. 2nd Edition, John Wiley and Sons, New York.

[26] Esen, H. (2008) Experimental Energy and Exergy Analysis of a Double-Flow Solar Air Heater Having Different Obstacles on Absorber Plates. Building and Environment, 43, 1046-1054. https://doi.org/10.1016/j.buildenv.2007.02.016

[27] Obaid, Z.A.H., Al-Damook, A. and Khalil, W.H. (2019) The Thermal and Economic Characteristics of Solar Air Collectors with Different Delta Turbulators Arrangement. Heat Transfer-Asian Research, 48, 2082-2104. https://doi.org/10.1002/htj.21472

[28] Ong, K.S. (1995) Thermal Performance of Solar Air Heaters: Mathematical Model and Solution Procedure. Solar Energy, 55, 93-109. https://doi.org/10.1016/0038-092X(95)00021-I

[29] Khalil, W.H., Obaid, Z.A.H. and Dawood, H.K. (2019) Exergy Analysis of Single-Flow Solar Air Collectors with Different Configurations of Absorber Plates. Heat Transfer-Asian Research, 48, 3600-3616. https://doi.org/10.1002/htj.21558 